\title{
An Investigation into Noxious Circulation of Indoor Molds in Residential Apartments: A Case Study Of Uturu Hostels, Abia State, Nigeria
}

\author{
Ananso G.N, Inyang-Enin A.O, Egege C.C and Omange O.Mary \\ Nigerian Building and Road Research Institute (NBRRI) \\ Federal Ministry of Science and Technology \\ Abuja, Nigeria.
}

\begin{abstract}
Fungal growth in damp buildings worldwide is an increasing problem which has adverse effects on both the occupant and the building. Hence, this study looks into the need to protect human health from mycotoxins through the analytical method in mycological examination and culture. It further elucidates problems with the microfungal infestation in buildings. Air and dust samples were collected by settle plate method and swabbing respectively, samples were cultured on Sabroud Dextrose Agar. The quantitative and qualitative analyses were done using systematic toxicological method for isolation and identification of molds. The microflora genera most frequently isolated were Penicillium spp, Aspergillus fumigatus, Aspergillus flavus, Aspergillus niger, Cladosporium spp, Fusarium spp. They occurred at an average number of 39, 26, 15, 27, 7 and 5 respectively. These organisms are of public health importance. Therefore, this result justifies the need to incorporate antifungal substances into some walling materials such as; paint, cement.
\end{abstract}

Keywords: Mycotoxins, Sabroud Dextrose Agar, Antifungal, Mold.

\subsection{INTRODUCTION}

Micro-organisms are frequently found in the lower portion of the troposphere where they are dispersed by air currents [Niemier, 2006 Most of the viable microbes present include a group of eukaryotic \{possess true nucleus\} non-photosynthetic microorganism known as FUNGI. They vary in complexity and size ranging from the single cell microscopic yeast to multicellular molds, macroscopic puffballs and mushrooms. However, they grow in two basic forms, The YEAST and MOLD \{Prescott et al; $2005\}$.

- The objective of this work is to determine the fungal load and the type of toxigenic molds present, and the effects on buildings and human.

Molds are microscopic fungi which are composed of long filaments called hyphae, possessing visible masses known as mycelia. These organisms are part of our natural environment; they are ubiquitous in nature, indoor and outdoor all year round. Although mold spores are constant in air, however, they are not usually a problem unless spores settle on damp spots then they proliferate. Molds reproduce by creating viable spores that are not usually seen without magnification. All molds are chemoautotroph's and share the characteristics of being able to grow without sunlight. Their toxin production depends on factors such as;

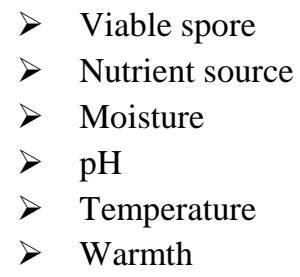

This explains why mold infestation is often found in damp and dark hidden spaces \{Tortora et al; 2008\}. Molds can grow on virtually any substance as long as moisture, oxygen and an organic source are present. They digest whatever complex substance they come in contact with to survive when they convert them to simpler ones. They grow on wood, leather, paper, carpet, food, 
basement, bathroom, ground floors, refrigerator, sinks, window sills, insulation while others feast on the everyday dust and dirt that gather in the moist regions of a building and deteriorate the building overtime. $\{$ Schiegel; 2007\}

Exposure to molds vary from one climatic region to another \{humid or windy\} home construction design and use of varying heating and cooling, humidifying, dehumidifying devices \{heat extractors $\}$ and air filling devices \{fan\}. Outdoor factors such as shades, organic debris near the homes and landscape maintenance also influence indoor concentration of molds. \{Globert and Patterson; 2007\}

\subsection{Effects Of Molds On Buildings}

Indoors, mold spores give rise to problems when they start eating away at materials affecting the look and smell especially with respect to wood-framed buildings. Gradually, they damage building materials and furniture if left unattended; they can eventually cause structural damage to buildings, weaken floors and walls as they feed on moist cellulose structural members in persistently humid and wet areas. \{Sudakin, 1998\}

The prevalence of molds in buildings could be attributed to natural disaster such as flooding and human errors such as, improper plumbing, infiltration of rain through leaking roofs, landscaping or gutters that direct water into or under the building i.e., improper drainage system, absence of damp-proof membrane, absence of damp-proof course, unvented combustion appliance, inadequate foundation etc \{National institute for occupational safety and health, 1970\}

Invariably, some moisture problems in buildings have been linked to changes in building construction practices since the 1970s, which resulted in tightly sealed buildings with diminished ventilation, contributing to moisture vapor build up, supporting the growth of mold \{ Fung and Hughson, 2007\}

Water vapors, when produced by human activities condense on cold surfaces like walls, organic building materials, window sills and furniture, Hence, accumulating moisture and these results to dampness, which overtime, aid in building deterioration.

\subsection{Health Effects}

Recently, there have been reports of severe illnesses as a result of indoor mold exposure, causing adverse health effects (known as, sick building syndrome) and producing allergens (substances that can cause allergic reactions) \{Andersson et al; 1997\} Allergic responses with putative symptoms which include hay-fever-type symptoms such as epistaxis, nasal and sinus congestion, red eye, migraine, skin rashes, chest tightness even asthma attacks to those allergic to molds, as well as generalized gastrointestinal complaints.

Organ effects such as pulmonary, immunologic, neurologic and oncologic (tumors) disorders $\{$ Mazur et al, 2003\}

Review of literature reveals certain fungus-disease associated with human including ergotism, alimentary toxic aleukia and liver disease. These were caused by Claviceps, Fusarium, and Aspergillus species respectively which are common indoor molds. \{Pitt et al., 2002; $\{$ Bu' Lock; 2007\}

Similar patterns report that damp homes were a strong predictor of respiratory and other illnesses common in children. $\{$ WHO, $2007\}$

\subsection{METHODOLOGY}

\subsection{Study Area}

This work was done in Abia State University hostels, three hostels were considered, each hostel is a two-storey building comprising of ground, first and second floor. Three samples were collected from each building from making total of 9 samples.

\subsection{Sampling}

Visual and olfactory inspections were taken in identifying water damaged areas in the hostels and visible mold growth.

Samples were collected under normal room activity, by settle plate method. This allows for mold spores to settle onto Agar media by gravity.

2.3 Materials And Method 


\subsection{Culture and Subculture}

Air samples were collected by means of exposing already prepared contact plates containing 100\% Sabroud Dextrose Agar. Dust samples were collected by swabbing. The culture Plates were incubated at 25 degrees $\mathrm{C}$ for 5 days. Fungal growths were sub cultured into sterile SDA plates using spot inoculation method, with aseptic techniques. Colonies were counted using solid agar colony counting method.

\subsection{Fungal Identification}

Identification of fungi in samples was done directly on SDA contact plates using the method of morphology and characterization in mycology (macroscopic colonial appearance) Fungi were identified to appropriate species and genera using direct microscopy after wet mount staining with lactophenol methylene blue and identification was made according to the methods described by Domsch et al; De hoog, et al; and Samson et al; 2006.

The qualitative analysis was done to reveal the fungi present and quantitative analysis to reveal the number of colonies present.

\subsection{DISCUSSION OF RESULTS}

The results obtained showed that the number of colony forming unit per hour varies with houses at different ground level.

\subsection{GROUND FLOOR}

Penicillium species isolated were 39, 23 and 28 in hostels' A, B, and C respectively. Aspergillus fumigatus isolated were 26,19 and 31 in hostels' A, B, and C respectively. Aspergillus flavus isolated were 15 in hostels' A and 21 in hostel C. Aspergillus niger isolated were 27, 30 and 37 in hostels' A, B and C respectively. Cladiosporium species was only present in hostel B and Fusarium species was present in only hostel B.

\subsection{FIRST FLOOR}

Penicillium species isolated were 16, 20 and 18 in hostels' A, B and C respectively. Aspergillus fumigatus isolated were 23, 17 and 23 in hostels' A, B and C respectively. Aspergillus flavus isolated were 13, 21 and 15 in hostels' A, B, and C respectively. Aspergillus niger isolated was 20,6 and 19 in hostels' A, B and C respectively.

\subsection{SECOND FLOOR}

Penicillium species isolated were 15, 10 and 12 in hostels' A, B and C respectively. Aspergillus fumigatus isolated were 14, 7 and 6 in hostels' A, B and C respectively. Aspergillus flavus isolated were 8, 6 and 10 in hostels' A, B and C respectively. Aspergillus niger isolated was 7, 19 and 15 in hostels' A, B and C. The number of colony forming unit per hour (CFU/Hr) in the ground floor was high as a result of high fungal load which was predicted right from the visual and olfactory inspection. 
International Journal of Engineering Research And Advanced Technology, Vol.5, Issue 4, April -2019

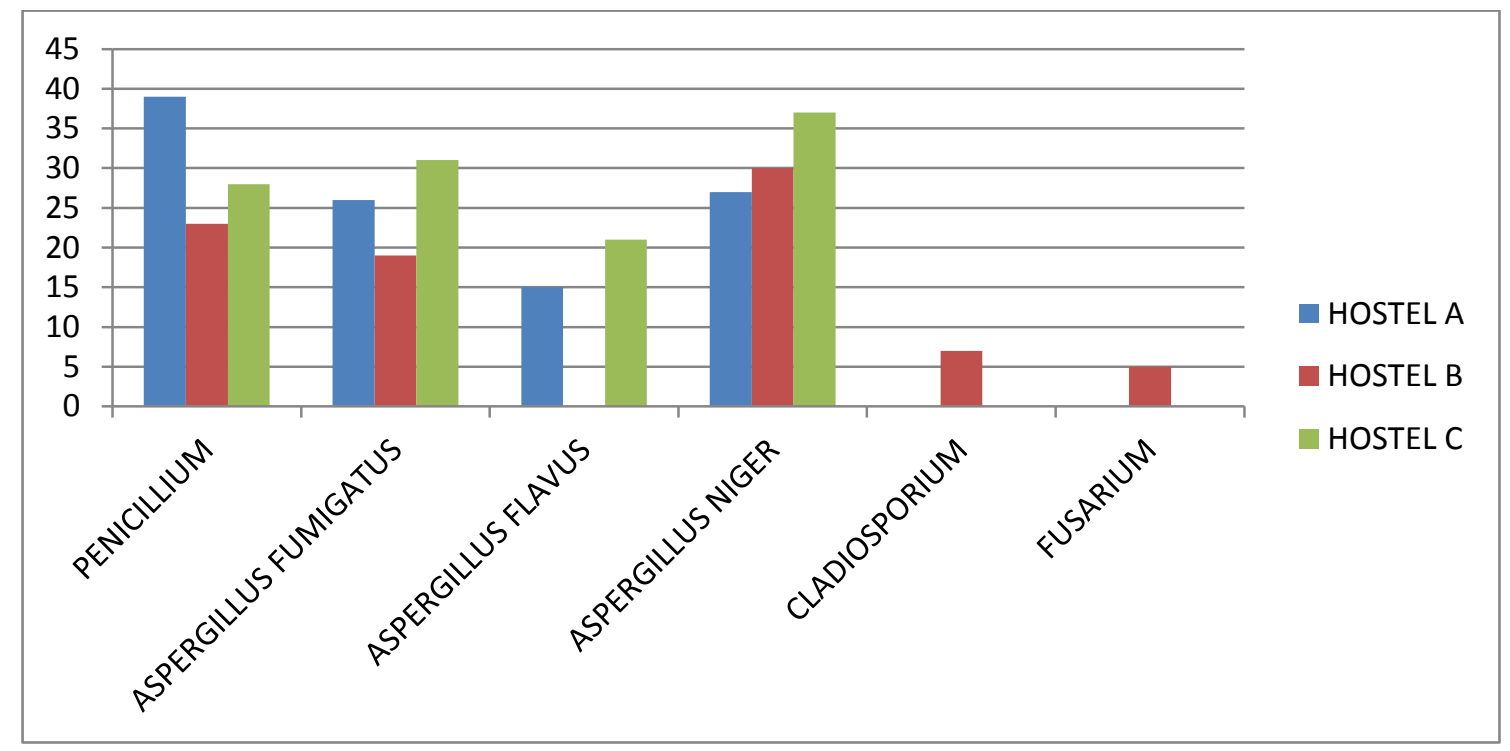

FIG. 1: SHOWING THE DISTRIBUTION OF MOLDS IN GROUND FLOOR

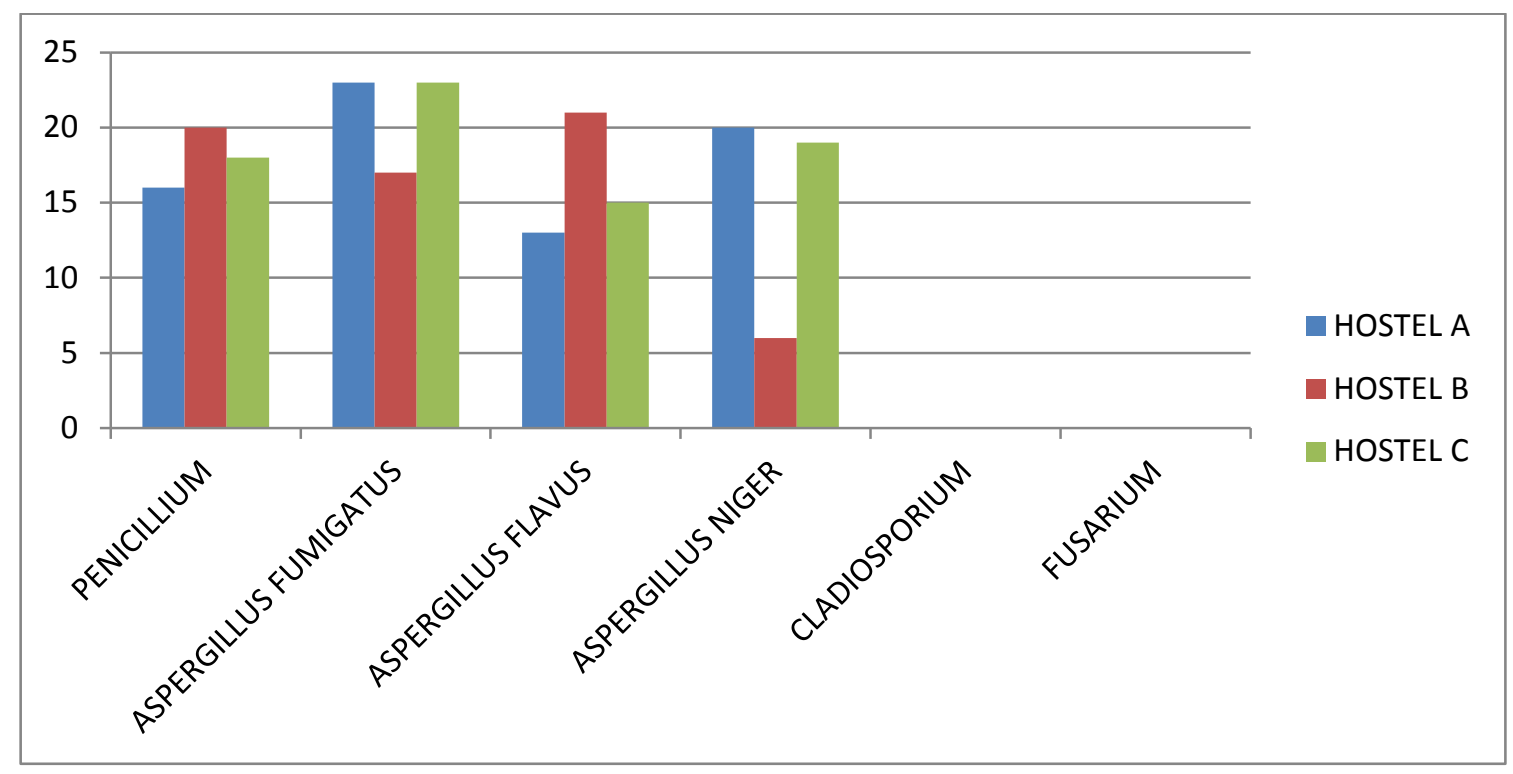

FIG. 2: SHOWING THE DISTRIBUTION OF MOLDS IN FIRST FLOOR 




FIG. 3: SHOWING THE DISTRIBUTION OF MOLDS IN SECOND FLOOR

\section{CONCLUSION}

In conclusion, the ground floors had the highest fungal load due to their locations. Toxigenic molds are ubiquitous and they are almost impossible to be completely eradicated. However, the key to curb infestation of mold is moisture control.

\section{RECOMMENDATION}

$>$ Further work should be done on the results obtained in the aspect of developing new resistant building materials by incorporating antifungal substances into paints and walling materials.

$>$ Ensure that the foundation is adequate.

$>$ In cases of water logged areas or places where the water table is high, the use of damp proof membrane and damp proof course is inevitable.

Faulty plumbing should be fixed as soon as possible.

$>$ Proper ventilation and the use of dehumidifier should be encouraged.

\section{REFERENCES}

1. Andersson, M.A; Nikulin, U. Koljalg, M.C. Andersson, F. Reijula, E.L. Hintikka, and M. Salkin-Oja-Salonen. 1997. Bacteria, molds and toxins in water-damaged building materials. Appl. Environ. Microbiology. 63:387-393.

2. Belanger K, Beckett $\mathrm{N}$ and Triche E. 2003. Symptoms of wheezing and persistent cough in the first year of life: Associations of indoor allergens, air contaminants and maternal history of asthma. Am. J. Epidemiology. 158: 195-202.

3. Bondy, G.S; and Pestka, J.J. 2001. Immunomodulation by fungal toxins. J. Toxicol. Environ. Health Ser. B 3: 109-143

4. Bu'Lock, J.D. 2004. Mycotoxins as secondary metabolites, Pg. 1-16.

5. Centers for Disease Control and Prevention. 2000. from CDC. Update: Pulmonary hemorrhage/hemosiderosis among infants. 1993-1996. JAMA. 283:1951-1953

6. Ciegler, A; and J. W Bennett. 2007. Mycotoxins and mycotoxicosis. Bioscience. 30: 512-515 Appl.Occup. Environ.Hyg. 18: 535-554

7. Environmental Protection Agency, 2012. From EPA. Update:

8. Globert and Patterson. 2007. Plumonary allergic aspergillosis. Ann. Intern. Med. 72:393.

9. Mazur, L. J and Klein J. 2003. Spectrum of noninfectious health effects from molds. Am. Acad. Ped. 118: 1909-1912

10. National institute for occupational safety and health, 1979. (NIOSH) Occupational safety and health administration Heating/Ventilation/Air conditioning System (HVAC)

11. Neimier, C.J; 2006. Microbiology journal. Inc. Arch. Occup. Environ. Health. 38:207

12. Prescott, L. M, Harley, J. P and Klein, D. A. $20056^{T H}$ edition. McGraw Hills companies, Inc. New York. Pp. 46.

13. Scheigel, H.G. 1993. General Microbiology. $7^{\text {th }}$ edition. Edited by Zaborosh and Kogut M. Cambridge University Press. The Pitt building Trumpington Street, Cambrigde CB2ie, United Kingdom, Pp, 40 
International Journal of Engineering Research And Advanced Technology, Vol.5, Issue 4, April -2019

14. Sudakin, D.I. 1998. Toxigenic fungi in a water damaged building: Intervention study. Am. J. Int. Med. 34: 183-190

15. Tortora, G.J. Funke, B.R. and Case, C.L. Microbiology an introduction

16. World Health Organization. 2007. Indoor Air Pollutants exposure and Health effects. Copenhagen Denmark. Europe reports and studies. No 78

Appendix



Penicillium spp.

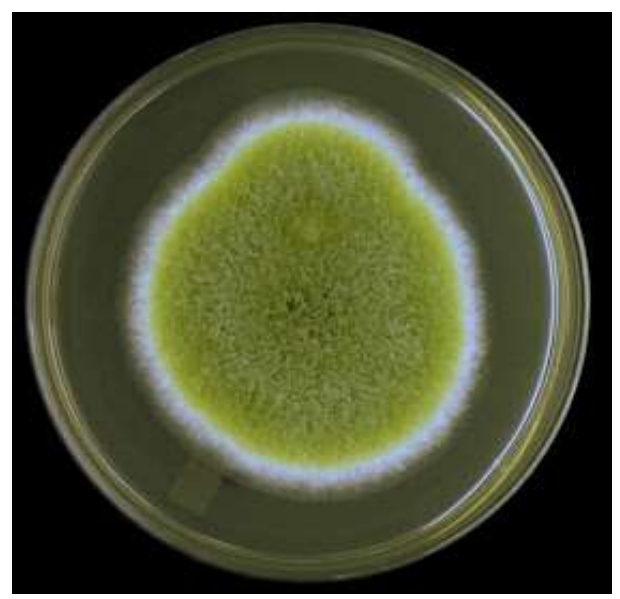

Aspergillus flavus

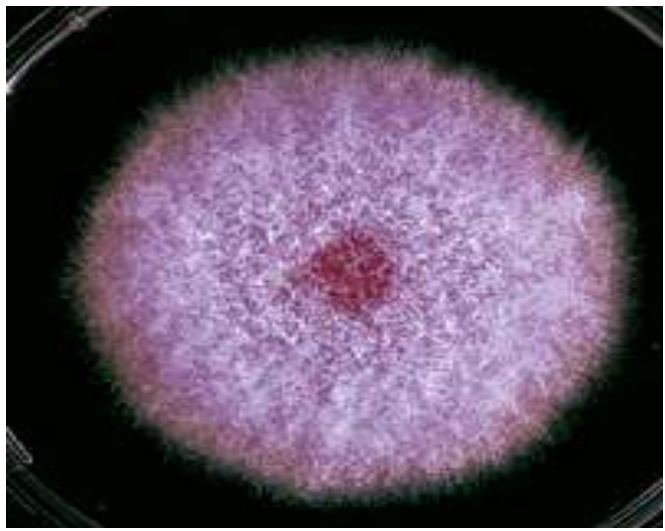

Fusarium spp

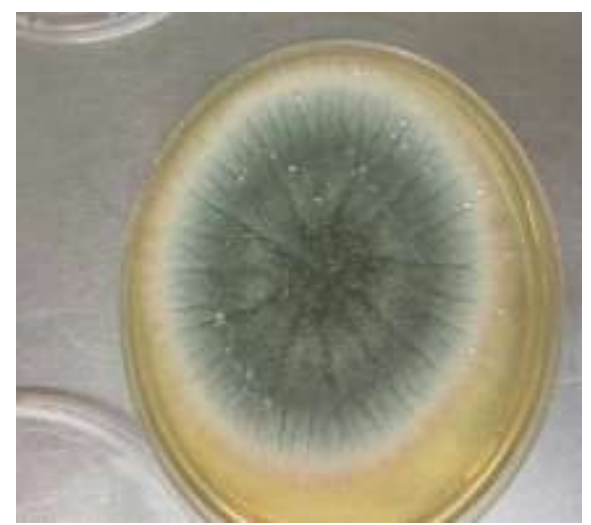

Aspergillus fumigatus

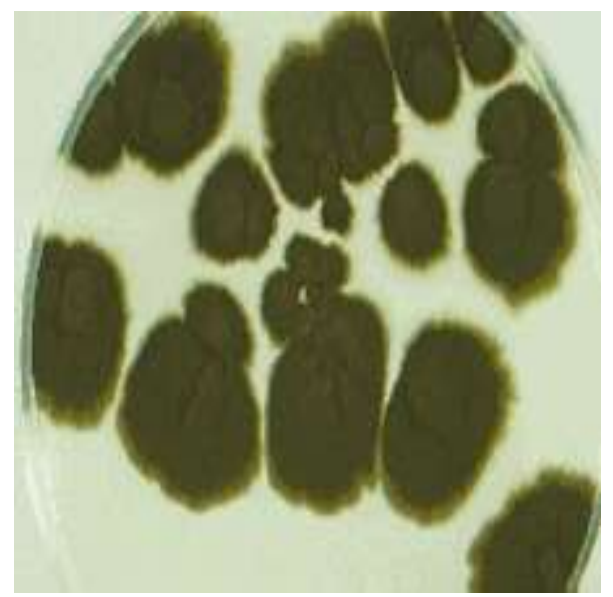

Cladiosporium spp 


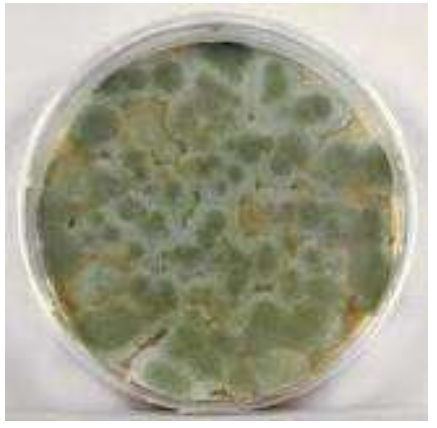

Penicillium spp.

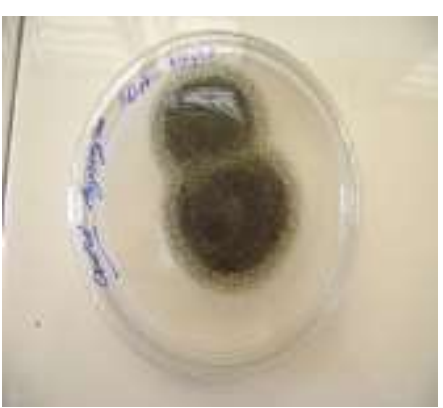

Aspergillus niger

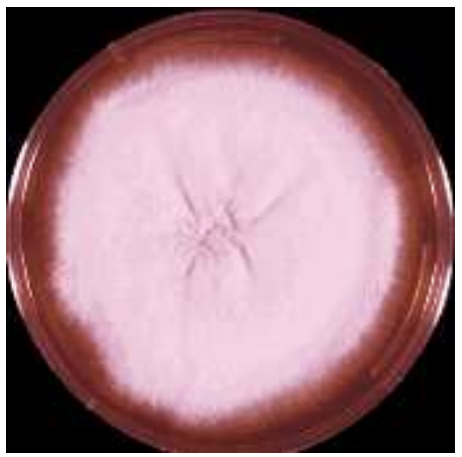

Fusarium spp

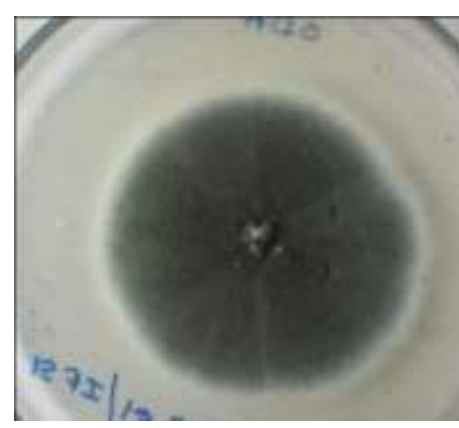

Aspergillus fumigatus



Cladiosporium spp



\section{REFERENCES}

1. Easton, B. (2008). Does poverty affect health? In K. Dew \& A. Matheson (Eds.), Understanding health inequalities in Aotearoa New Zealand (pp. 97-106). Dunedin, New Zealand: Otago University Press.

2. Rush, E., McLennan, S., Obolonkin, V., Cooper, R., \& Hamlin, M. (2015a). Beyond the randomised controlled trial and BMI--evaluation of effectiveness of through-school nutrition and physical activity programmes. Public Health Nutrition, 18(9), 1578-1581. https://doi.org/10.1017/S1368980014003322

3. Rush, E. C., Obolonkin, V., Battin, M., Wouldes, T., \& Rowan, J. (2015b). Body composition in offspring of New Zealand women: Ethnic and gender differences at age 1-3 years in 2005-2009. Annals Of Human Biology, 42(5), $492-497$.

4. Li, S., \& Seale, C. (2007). Learning to do qualitative data analysis: An observational study of doctoral work. Qualitative Health Research, 17(10), 1442-1452. https://doi.org/10.1177/1049732307306924

5. Barnard, R., de Luca, R., \& Li, J. (2015). First-year undergraduate students' perceptions of lecturer and peer feedback: A New Zealand action research project. Studies In Higher Education, 40(5), 933-944. https://doi.org/10.1080/03075079.2014.881343 
6. Szcz Ę Sna, A., Nowak, A., Grabiec, P., Paszkuta, M., Tajstra, M., \& Wojciechowska, M. (2017). Survey of wearable multi-modal vital parameters measurement systems. Advances in Intelligent Systems and Computing, 526. https://doi.org/10.1007/978-3-319-47154-9_37

7. Kasabov, N., Scott, N. M., Tu, E., Marks, S., Sengupta, N., Capecci, E., . . Yang, J. (2016). Evolving spatio-temporal data machines based on the NeuCube neuromorphic framework: Design methodology and selected applications. Neural Networks, 78, 1-14. https://doi.org/10.1016/j.neunet.2015.09.011 